\title{
... COMO SI EL POETA NO PERTENECIESE AL PUEBLO: LOS CANTARES DE RUIZ AGUILERA EN EL REPERTORIO FLAMENCO
}

\author{
... As if the Poet did not Belong to the Folk. The "Songs" \\ of Ruiz Aguilera in the Flamenco Repertoire
}

\author{
Antonio Plaza Orellana \\ Profesor de música de enseñanza secundaria. IES Julio Verne (Sevilla) \\ antonplazaore@gmail.com
}

Recibido: 12/01/2020; Aceptado: 12/06/2020; Publicado: 31/12/2021

Ref. Bibl. ANTONIO PLAZA ORELLANA. ... COMO SI EL POETA NO PERTENECIESE AL PUEBLO: LOS CANTARES DE RUIZ AGUILERA EN EL REPERTORIO FLAMENCO. 1616: Anuario de Literatura Comparada, 11 (2021), 33-58

RESUMEN: El siguiente artículo valora la repercusión en el flamenco de los cantares de Ventura Ruiz Aguilera, uno de los poetas más relevantes de la denominada "poesía de cantares", corriente literaria que irrumpe en la segunda mitad del siglo XIX. La técnica imitativa del cantar popular, el carácter epigramático y el compromiso social dotan a nuestro poeta de un lenguaje cercano que permite que se popularicen muchas de sus creaciones. La pervivencia de tradiciones musicales basadas en la interpretación sucesiva de coplas constituye un medio idóneo en el que se conservan sus cantares de forma anónima. Aunque algunos investigadores no han considerado el estilo de nuestro poeta afín a la tradición andaluza, trataremos de analizar aquellas estrofas que se afianzan en el corpus flamenco.

Palabras clave: cantares; flamenco; fandango; copla; popular; folklore. 
ABSTRACT: The following article assesses the impact on flamenco of the "Cantares" (songs) of Ventura Ruiz Aguilera, one of the most relevant poets of the so-called "poesía de cantares" (song poetry), literary trend that appears in the second half of the 19th century. The imitative technique of popular singing, the epigrammatic character and social commitment define our poet with a close language that allows many of his creations to become popular. The survival of musical traditions based on the successive singing of couplets constitutes an ideal medium in which their "cantares" are preserved anonymously. Although some researchers have not considered the style of our poet related to the Andalusian tradition, we will try to analyze those stanzas that are entrenched in the flamenco repertoire.

Key words: cantares (songs); flamenco; fandango; couplet; popular; folklore.

\section{Pero El PUeblo le dijo: ... NO TE CONOZCO}

El anhelado sueño de inmortalidad de todo artista por el recuerdo de su obra se vuelve paradoja en el caso de Ventura Ruiz Aguilera. De ser uno de los poetas sociales de mayor repercusión en la segunda mitad del siglo XIX, apenas quedarán ecos en el ocaso del siglo. Las altas torres de su edificio, como la "Epístola» que Menéndez Pelayo incluirá entre las Cien mejores poesías de la lengua castellana, quedarán inhabitadas por el paso del tiempo; sin embargo, sus pequeños cantares sí perdurarán en las distintas tradiciones folklóricas del mundo hispano. La paradoja desemboca en ironía si tenemos en cuenta la anonimia característica de estas piezas populares; anonimia contra la que Ruiz Aguilera fue un rocoso combatiente.

A lo largo de este artículo intentaremos resaltar la importancia del poeta salmantino en la lírica popular hispana, ya que, junto a Augusto Ferrán, Ramón de Campoamor y Melchor de Palau, conformarán las corrientes más importantes de lo que se ha dado en llamar "poesía de cantares". Esta tendencia literaria se desarrolla en los albores de la década de 1860, siguiendo la estela de autores germanos como Heinrich Heine. Augusto Ferrán, traductor del poeta alemán, o Ramón de Campoamor, admirador del mismo, renovarán el lenguaje romántico amoldándolo a las formas poéticas características de la lírica popular.

Este acercamiento sin complejos de la poesía culta a la popular se estructura sobre pequeñas formas; principalmente cuartetas asonantadas, seguidillas simples y con estribillo, seguidillas gitanas y soledades. La amplia difusión de las mismas deriva del desarrollo de los esquemas musicales estandarizados que las sustentan. El resultado es una obra musical con escasa relación entre texto y música, pero de gran libertad literaria. Géneros 
musicales hoy día considerados tradicionales, como jotas, fandangos o seguidillas, extendidos en multitud de variantes por las distintas herencias folklóricas, constituyen buenos ejemplos de estos esquemas sonoros. En la mayoría de los casos, la variante melódica no repercute en la forma poéti$\mathrm{ca}$, que, pese a adquirir modificaciones en forma de interjecciones, versos tópicos y estribillos, permite reconocer estos patrones métricos. La amplia difusión de estos estilos posibilita localizar una misma copla en patrimonios musicales distantes, ya que comparten una forma poética similar.

El género parece eclosionar en 1860 con los cantares personales que Augusto Ferrán recopila en La Soledad. En 1861 aparecen nuevos autores, pero destacamos las numerosas muestras en prensa de las redondillas de Ramón de Campoamor, que, según algunos investigadores, podrían estar ya publicadas en torno a 1857. Ruiz Aguilera otorga la paternidad a Ferrán y polemiza con Antonio de Trueba, quien pretendió su atribución, pero su Libro de los Cantares se mueve en una línea de inspiración popular sin el criterio estrófico de las coplas, al igual que los anteriores Ecos nacionales de nuestro autor. Sus cantares los encontramos por primera vez en 1862, en la selección del almanaque de El Museo Universal para 1863. Las primeras críticas elogiosas las hemos localizado en la gacetilla de prensa de El Contemporáneo, que se hace eco de una reunión literaria en casa de Eduardo Asquerino. El cronista valora la capacidad sintética del género: "Nada más difícil que encerrar en cuatro versos y en estilo llano y vulgar, un poema de ternura o una profunda sentencia o un quejido del alma» (Anónimo 1863, 4).

La definición de "literatura popular» se encuentra en continua revisión, matizándose con conceptos como «semipopular», "popularizada" o "popularizante»; que surgen para intentar asimilar la participación del poeta letrado en el repertorio lírico anónimo. Frente a una sociedad decimonónica que aún mantiene vivo el mito romántico de la Naturpoesie, es decir, la poesía natural inherente e instintiva que nace del pueblo, Ventura Ruiz Aguilera se posiciona en contra. En la defensa de la inspiración culta en las creaciones populares serán referentes alegatos de su pluma; entre ellos, el prólogo a Armonías y cantares o artículos como "Sobre la colección de cantares atribuidos al vulgo", donde afirmará: "Los que conceden al pueblo (quiero decir, al vulgo) facultades que tal vez niegan a poetas de raza, como si el poeta no perteneciese al pueblo, como si el poeta no hubiese tenido contacto con él» (Ruiz 1864, 246). Esta distinción entre pueblo y vulgo marcará la línea de su tesis. Como anécdota, comentamos que la famosa cita de Alfonso $\mathrm{X}$, que suele esgrimirse con frecuencia en este litigio y que aclara que «debe entenderse por pueblo el ayuntamiento de todos los omes comunalmente, de los mayores, é de los medianos, é de los menores..., no la gente 
menuda, assi como menestrales, é labradores», fue lucida inicialmente por Ruiz Aguilera, antes de ser elogiada en los trabajos de Menéndez Pidal.

Esta discusión se encona en el flamenco; un género muy reforzado por el Volkslied, que mantiene el debate hasta nuestros días. La distinción establecida por muchos investigadores del género entre cantes gitanos (o gitano-andaluces) y cantos populares trata de alejar la pluma creadora del poeta culto de las inspiradas soleares y seguiriyas atribuidas a sus intérpretes. Esta atribución es habitual en el cante flamenco, en el que la intensidad del "yo lírico" favorece esta asociación y hace que el ejecutante emita un mensaje como si fuera suyo (Fernández y Pérez 1983, 54). No con esto queremos eludir el talento de muchos cantaores de gran creatividad literaria. Recordemos la alusión de Machado Álvarez, pionero en la investigación del género, a la única copla de Augusto Ferrán incluida en la Colección de cantos flamencos: "Merece plenamente el título de popular, título, que muy pocos cantares de eruditos logran merecer» (Machado 1881, 66). Más doloroso para Ruiz Aguilera será el empleo por parte de Rodríguez Marín de sus cantares XXXVIII y XC como ejemplos del cantar popular "pulido", libre de cultismos (Rodríguez 1882-1883, 123).

El debate sigue abierto, e investigadores actuales como José Gelardo Navarro subestiman en Acerca del carácter popular de la copla flamenca la aportación de estos poetas:

[los autores cultos] demuestran tener una exquisita sensibilidad y comprensión de la poesía popular y de la poesía flamenca anónima. Sin embargo, no es cierto que, de manera general, sus poemas hayan pasado a la tradición flamenca; queremos decir que no han sido asumidos por los cantaores por la sencilla razón de que, en general, no son flamencos; también, porque ambos, el poeta de cultura escrita-erudita y el poeta-cantaor flamenco, de cultura oral-vocal, pertenecen a clases sociales diferentes, incluso antagónicas. (Gelardo 2016)

No pretendemos en el siguiente artículo reabrir este complejo debate. Con él tratamos de acercar la obra de uno de los muchos creadores de estrato social y cultural diverso que han contribuido a ampliar el imaginario flamenco.

2. ESTILO Y PERSONALIDAD. "DESPUÉS DE HACERTE, DiOS QUISO PONER UN LUNAR POR FIRMA..."

La preocupación social rige el estilo creativo de Ruiz Aguilera, que se aleja de la idea elitista del poeta elevado. En el prólogo de los Ecos 
nacionales, ya anuncia su intención de "popularizar la poesía moderna, para sacarla del gabinete del literato... y hacerla penetrar en el círculo de la clase media, del artesano y en la choza del labrador» (Ruiz 1849, XI). Con un discurso aún muy impregnado de la Volkspoesie romántica, defiende la inspiración comprometida reflejada en el espejo popular:

[La tarea de los poetas modernos] no debe ser otra que estudiar el espíritu del siglo; conocer la sociedad en que viven [...] la fisonomía del pueblo, del gran carácter social, o, lo que es lo mismo, la copiosa fuente de donde han de tomar los poetas sus inspiraciones. (Ruiz Aguilera 1849, VIII)

Es arriesgado establecer afirmaciones tajantes si atendemos a la heterogeneidad intencionada que suele imperar en las colecciones de cantares, que pueden presentar más de doscientas muestras. En ellas, la variación de estilo y carácter aporta diversidad a la amenazante monotonía de un espíritu fiel a una técnica y personalidad. En nuestro caso, la vertiente estilística que aporta Ruiz Aguilera a los cantares literarios muestra una línea distintiva respecto a otras corrientes. De ella destacamos principalmente su técnica creativa, basada en la imitación de las coplas populares, pero sin la identificación ni el anhelo mimético que pretendía Augusto Ferrán. De Castro García denota un compromiso pedagógico inherente al creador culto que, con la adopción de giros y expresiones coloquiales, pretende elevar la poesía popular a la esfera artística (De Castro 1988, 305). En esta línea, Gutiérrez Carbajo distingue incluso un anhelo de universalidad con la preocupación del autor de traducir muchas de sus obras, entre ellas los cantares, a varios idiomas (Gutiérrez 1990, 231).

José María de Cossío apunta influencias de otras corrientes de cantares, como las de Ferrán o Campoamor, de claro parentesco con la poesía de Heinrich Heine. Ferrán adopta un sentido pesimista y Campoamor un compromiso aleccionador. La profesora De Castro García determina que este parentesco es insignificante en los cantares de Aguilera en los que el tono desengañado y pesimista no se prodiga (De Castro 1988, 308).

Pese a que la temática predominante es la amorosa, y la imitación de coplas populares impera, el tono moralizante y edificador se filtra en muchos de sus cantares. Lledó Patiño destaca el compromiso social que impone Ruiz Aguilera al artista creador como fundamento para la distinción entre poesía popular y poesía vulgar:

Ventura Ruiz Aguilera establece una importante diferencia entre poesía popular -la que él escribe, que se inspira en el pueblo todo- y poesía vulgar -poesía que se inspira exclusivamente, con raras excepciones, en la última clase del pueblo; o en otros términos, en la clase inculta-. Ruiz Aguilera se aleja -más bien huye- de esta forma de escribir para la masa 
para obtener su pleitesía y los favores mayoritarios que repercuten en el bolsillo del escribiente. (Lledó 2006, 144)

El activismo social se distingue por la presencia en algunos de sus cantares de temas como la pobreza o la prostitución. Ventura Ruiz Aguilera une sus esfuerzos a los del krausismo en la reforma pedagógica preconizada desde la revolución progresista de 1868, una de cuyas misiones es la de atenuar la discriminación de la mujer (Lledó 2006, 191). Este tema ha sido escasamente planteado hasta el momento sin terminar de cuajar en el género de cantares, pese al acercamiento décadas después de otros poetas como Enrique Paradas. En el caso del flamenco será veladamente tratado en su repertorio hasta los «dramáticos» fandangos del siglo Xx. Citamos algunos ejemplos:

Años ha, la vi de noche,

Desnuda, hambrienta y llorosa;

Ayer pasó en carretela

Como fantástica sombra:

Y siempre lástima diome;

Que, si antes el cuerpo flaco,

Ayer la infeliz llevaba

Cubierta el alma de andrajos.

(XCVIII) (Ruiz 1865, 114)
El lujo de esa pobre

Ya no me extraña:

Para vestir el cuerpo

Desnuda el alma.

(LXXVIII) (Ruiz 1865, 106)
El que a los pobres se baje

No baja su condición,

Pues la pobreza la quiso

El mismo Dios, con ser Dios.

(XXXVII) (Ruiz 1865, 91)

El carácter filosófico sí podría llevarnos a establecer cierto paralelismo con los cantares en redondilla de Campoamor, pero el padre Blanco García establece una leve línea divisoria:

El género de los Cantares, extraordinariamente fecundo en nuestra literatura del siglo XIX, estaba muy conforme con las aficiones de moralista tan visibles en Ruiz Aguilera, quien, si no alcanza en ellos la filosofía maleante y sui generis de los de Campoamor, ni imita de los compuestos por el vulgo la exactitud gráfica y pintoresca, conserva de estos últimos el tono uniformemente sencillo en cuanto lo permite la variedad de los asuntos. (Blanco 1903, 128)

La apacible crítica de Blanco García se hace algo más severa al tratar el sentido religioso del poeta, de cuya franqueza desconfía:

Es el de Ruiz Aguilera un cristianismo racionalista, de sinceridad dudosa, y que se paga excesivamente del sentimiento [...] sus versos religiosos obedecen, no tanto a la idea católica en toda su integridad, como a las vaguedades del teísmo más o menos divorciado de la enseñanza evangélica. (Blanco 1903, 125) 
La materia religiosa es escasamente tratada por los primeros poetas de cantares. Si estas coplas populares basculan entre la sencillez e ingenuidad del rezo infantil y la más severa condenatoria, los cantares de Ruiz Aguilera responden a contrastes similares; manteniendo el tono prosaico y romanceado que las caracteriza:
En el costado de Cristo Mamando Judas, cuentan
Los brazos de la Cruz santa, De sangre una fuente mana, Que habló, diciendo: Siempre abiertos significan, De sangre tan pura y limpia "¿Quién me compra a mi madre? Muchas culpas en el hombre; Que nuestros pecados lava. Que yo la vendo." (XCIX) (Ruiz 1865, 114) （CXI) (Ruiz 1865, 120) En Dios clemencia infinita. (CXLII) (Ruiz 1865, 132)

La distancia con Ferrán parece radicar más en el matiz pesimista que impregnan los cantares del madrileño. El sentido jocoso patente en muchas coplas de Ruiz Aguilera marca una distancia insalvable respecto al páramo humorístico de las muestras de Ferrán. Al igual que otros autores que cultivan la ironía, como Manuel del Palacio o Carlos Cano, conseguirá camuflar sus cantares en colecciones como Flor de epigramas. El marcado pesimismo de gran parte de la lírica flamenca ha generado reflexiones estéticas que lo han interpretado -en uno de los argumentos más recurrentes- como una consecuencia del desamparo vital que sufre el individuo ante el cosmos, cuya incapacidad intelectual de respuestas degenera en una devaluación de las fuentes del conocimiento. Ruiz Fernández ha definido irónicamente como «teorema jondo de insuficiencia» esta tendencia en la que la ciencia resulta insuficiente para explicar la totalidad del mundo (Ruiz 2019, 35), de ahí versos como "presumes que eres la ciencia", "estando un sabio en su agonía» o "el saber de ná le vale», que nos llevan a una depreciación de la cultura. La presencia del humor en las coplas de Ruiz Aguilera quizá lo distancia del corpus flamenco más solemne, cuyo histrionismo evita cualquier proximidad al tono cómico, pero también poseen un cierto aire sentencioso y sentimental que no los hace ajenos al género. Como ejemplo y curiosidad destacamos la errónea atribución a Aguilera por parte de Luis Montoto del antiguo cantar: "La Nochebuena se viene, / la Noche buena se va, / y nosotros nos iremos / y no volveremos más", que el salmantino incluyó en La leyenda de la Noche-buena (Montoto 1893, 69). Insiste Cossío además en un matiz más pintoresquista que trataremos de analizar:

En Ferrán predomina la tendencia sentimental y vaga, junto con una inteligente asimilación de lo popular andaluz. En Campoamor predomina, como en el resto de su obra, el prurito que llamaban filosófico, y que no era incongruente con la vocación sentenciosa del pueblo testificada por tantas coplas suyas y refranes. Ventura Ruiz Aguilera, precisamente por la falta de individualidad relevante, tiene más a la vista los cantares 
populares, pero el hecho de no ser andaluz, le hace seguir distinto camino del de Ferrán... (Cossío 1960, 461)

\section{RuIZ y AgUILERA y lOS CANTOS ANDALUCES. "UNA ANDALUZA EN FRANCIA CALZARSE QUISO..."}

Las referencias explícitas a los cantares andaluces por parte del autor son las críticas al prólogo de José Joaquín de Mora de los Cuentos y poesías andaluces, de Fernán Caballero, y al Cancionero popular, de Emilio Lafuente Alcántara, que incluye en el artículo «Sobre la colección de cantares atribuidos al vulgo». La reprobación inicialmente se centra en la apropiación indebida que ejerce el acervo andaluz de un corpus lírico extendido por toda la nación: "Yo no he estado nunca en Andalucía, y desde que tengo uso de razón oigo en Castilla todos los [cantares] del libro de Fernán Caballero y otros no incluidos en él» (Ruiz 1866, 247), al tiempo que reclama el corpus lírico como un producto panhispánico. El fenómeno de identificación de las costumbres andaluzas como síntesis de las nacionales había sido una constante en los salones burgueses desde finales del siglo XVIII, donde se interpretaban en contraste a los repertorios de moda italiano y francés (Alonso 1998, 200). La influencia que ejerció el «género de costumbres andaluzas» en la cultura popular española adquiere especial intensidad entre 1830 y 1860, como se puede comprobar por las numerosas piezas escénicas, novelas o pliegos de cordel publicados.

Ruiz Aguilera se deja llevar de otros tópicos concediendo una virtud más pictórica que literaria a las regiones meridionales; privándolas de la "Concentración solitaria, íntima y serena de sí mismo" (Ruiz 1866, 248). Refuerza su teoría analizando los orígenes de los principales poetas de cantares del momento, entre ellos Ferrán, Isabel de Villamartín, Palau o Asensio de Alcántara. Ninguno de ellos es andaluz, quienes, ciertamente, son minoría; sin embargo, prescinde de autores como el cordobés Antonio Grilo o el portuense Ángel María Dacarrete, que también ve publicado su cantar "No me digas que te olvide», de forma anónima, en el Cancionero popular de Lafuente Alcántara. Pese a todo, no escatima palabras elogiosas a la cultura andaluza, a la que dedica algún cantar, además de los seis poemas póstumos que conforman Andalucía.

El término "flamenco", como referencia a un género musical, aparece por primera vez en prensa en torno a 1847, como ha localizado Alberto Rodríguez en los artículos de El Espectador, aunque ya hay indicios desde 1841, como observa Faustino Núñez, en el Fray Gerundio, de Modesto Lafuente. El empleo coloquial del término no estaba muy extendido, denominándose 
en su lugar "cantos andaluces" O "cantares andaluces", como en el artículo de Ruiz Aguilera. Las distintas líneas investigadoras intuyen que el género se va conformando en la primera mitad del siglo XIX, y sus peculiaridades estilísticas han planteado un debate histórico entre aquellos que la consideran una modalidad poética distinta de la naturaleza de la lírica popular. El ya citado folklorista Antonio Machado Álvarez, Demófilo, insinuó esta equidistancia respecto a la lírica popular, que fue objetada por lingüistas cercanos como Hugo Schuchardt, así lo hemos podido comprobar en la tardía traducción de su obra elaborada por Feenstra y Steingress (Schuchardt 1990, 33). Con un prisma más reciente, el profesor Gutiérrez Carbajo plantea una serie de rasgos que reconoce insuficientes para establecer dicha distinción. Elementos estilísticos como el patetismo, el especial tono lírico, el carácter urbano, la ausencia de paisaje, la especial intensidad en el tratamiento de temas como el amor, la muerte o la pena, e incluso los aspectos musicales y rítmicos, no permiten especificar un campo independiente (Gutiérrez 1990, 782). Tampoco favorece el análisis el hecho de establecer una mirada global al flamenco sin distinguir entre los distintos estilos que lo componen ni la diversidad que lo define. Pese a la similitud de formas poéticas entre los estilos flamencos -O "palos", que es la denominación habitual entre los asiduos al género- que nos permite encontrar un mismo cantar en estilos diferentes, no todos poseen similar carácter, aunque presenten un amplio cromatismo expresivo. El recogimiento y patetismo de las seguiriyas difiere de las festivas sevillanas o bulerías. Atendiendo a este distinto carácter, hemos numerado las referencias sonoras y literarias donde hemos localizado los cantares de Ruiz Aguilera y de otros autores contemporáneos a nuestro autor, para facilitar un perfil estilístico.

Tabla 1. Poetas de Cantares entre los distintos estilos flamencos

\begin{tabular}{|l|c|c|c|c|}
\hline & $\begin{array}{c}\text { Campoamor } \\
\text { (Cantares, } \\
1861)\end{array}$ & $\begin{array}{c}\text { Ferrán (La } \\
\text { Soledad, } \\
1861 ; \text { La } \\
\text { Pereza, } \\
1871)\end{array}$ & $\begin{array}{c}\text { Ruiz Aguilera (Armonías } \\
\text { y cantares, 1865; El libro } \\
\text { de la patria, 1869; Ecos } \\
\text { nacionales y cantares, } \\
1873)\end{array}$ & $\begin{array}{c}\text { Palau (Cantares, } \\
1866 ; \text { Nuevos } \\
\text { cantares, 1883; } \\
\text { Últimos cantares, } \\
1909)\end{array}$ \\
\hline $\begin{array}{l}\text { Malagueñas, } \\
\text { granaínas, } \\
\text { murcianas }\end{array}$ & 1 & 6 & 4 & 22 \\
\hline $\begin{array}{l}\text { Fandangos, } \\
\text { verdiales }\end{array}$ & 3 & 2 & 10 & 18 \\
\hline Soleares & 2 & 4 & 0 & 0 \\
\hline
\end{tabular}




\begin{tabular}{|l|c|c|c|c|}
\hline & $\begin{array}{c}\text { Campoamor } \\
\text { (Cantares, } \\
1861)\end{array}$ & $\begin{array}{c}\text { Ferrán (La } \\
\text { Soledad, } \\
1861 ; \text { La } \\
\text { Pereza, } \\
1871)\end{array}$ & $\begin{array}{c}\text { Ruiz Aguilera (Armonias } \\
\text { y cantares, 1865; El libro } \\
\text { de la patria, 1869; Ecos } \\
\text { nacionales y cantares, } \\
1873)\end{array}$ & $\begin{array}{c}\text { Palau (Cantares, } \\
1866 ; \text { Nuevos } \\
\text { cantares, 1883; } \\
\text { Ultimos cantares, } \\
1909)\end{array}$ \\
\hline Tangos & 2 & 4 & 2 & 1 \\
\hline Seguiriyas & 1 & 6 & 0 & 0 \\
\hline Peteneras & 2 & 2 & 0 & 1 \\
\hline $\begin{array}{l}\text { Alegrías, } \\
\text { sevillanas, } \\
\text { bulerías }\end{array}$ & 0 & 0 & 3 & 2 \\
\hline
\end{tabular}

Fuente: Elaboración propia.

Pese a estar musicalmente emparentados, hemos decidido separar el grupo de las malagueñas y el de los fandangos, para intentar establecer un sentido cronológico. Las malagueñas, plenas de lirismo, adquieren su popularidad en las últimas décadas del siglo XIX y las primeras del XX; y los fandangos, en una evolución del estilo, asumirán ese liderazgo a partir de la década de 1920. Comprobamos que la mayor difusión de sus cantares se encuentra entre los fandangos y los verdiales, estilos que fluctúan entre el repertorio individual del intérprete flamenco y la tradición popular colectiva. De manera similar ocurre con las sevillanas que, sobre la forma de seguidilla, pueden participar de una interpretación grupal. En el sentido opuesto destacamos su ausencia entre las soleares y seguiriyas, que requieren para su ejecución de una solemnidad particular. Quizá es debido a este carácter sentimental, el más singular del flamenco, por lo que Cossío pretende excluirlo de lo "popular andaluz":

Le falta verdadera personalidad, y se mantiene en un punto de equilibrio y de templanza que no es el menor aliciente de sus cantares. No podrían cantarse ciertamente con estilos de cante gitano ni aún andaluz, sino con las tonadas graves de Castilla en las que se serenan las pasiones, como el paisaje llano y severo bajo el sol. (Cossío 1960, 467)

Otra ausencia destacada son las peteneras; un estilo que gusta de la temática moralizante, en el que no hemos encontrado el eco de Ruiz de Aguilera. Los tangos, con dos muestras recientes, en su heterogeneidad temática, también gustan de expresiones sentenciosas y aleccionadoras. 


\section{ARMONÍAS Y CANTARES}

La obra se edita en 1865, con un conjunto inicial de poemas que conforman las "armonías» y una segunda parte que incluye los cantares, nuestro tema de estudio. Estos habían ido apareciendo en la prensa diaria y en semanarios culturales desde 1863. Algunos de ellos se incluirán en Inspiraciones, en 1865, y muchos volverán a incluirse en El libro de la patria en 1869. El medio de difusión real de sus cantares proviene de la prensa diaria, que irá insertando pequeñas muestras entre las gacetillas y secciones culturales aprovechando el gran acogimiento de este género entre sus lectores.

Poseemos constancia de la repentina popularidad que adquieren sus primeros cantares publicados en prensa. El famoso cantar LXV será citado por el firmante "Eduardo» entre las "Variedades» de La Abeja montañesa, popularizado entre el pueblo andaluz. Gutiérrez Carbajo recuerda que el político Emilio Castelar, con algunas variantes, lo había escuchado en labios de una gitana (Gutiérrez 1990, 233). La importancia de la prensa en la difusión de coplas se hace patente en el cantar «Cuando escribirme pretendas", también de la primera hornada de 1862, que será descartado de todas sus futuras recopilaciones. Aparece publicado frecuentemente en los diarios, siendo su único medio de dispersión literaria, y lo localizaremos de forma anónima entre los "Ayes y flores» de la recopilación Gorjeos del alma, del poeta y periodista Ricardo Caballero (Caballero 1884, 91).

No te pongas colorada

Al pasar por este valle,

Pues como no tiene lengua

No contará lo que sabe.

(LXV) (Ruiz 1863, 56)
No te pongas colorada

Cuando pases por mi calle,

Que como no tiene lengua

No contará lo que sabe.

(«Eduardo»1864, 3)
Cuando escribirme pretendas

De papel sírvate el agua,

Y así durará más tiempo

Lo que escribes en tus cartas.

(Ruiz 1863, 56)

Los cantares de mayor repercusión serán los dos que incluye Emilio Lafuente en su recopilación: el Cancionero popular. El primero de ellos es el cantar XVII, del que encontramos numerosas coplas populares que podrían haber servido de modelo. La metáfora bíblica de la torre como símbolo de arrogancia humana y soberbia, más allá de los límites impuestos por Dios (Longman, Willhoit y Riken 2015, 245), constituye un atavismo dentro de la lírica popular. Citamos como ejemplo la conocida tirana que incluye Juan Antonio Iza de Zamacola, Don Preciso: «De la torre de mis gustos / en lo más alto me vi; / los cimientos fueron falsos, / otro subió, yo caí» (Iza de Zamacola 1816 I, 172), que también se inspira en la Torre de Babel. El cantar de Ruiz Aguilera está muy extendido por numerosas tradiciones hispanas, además 
del flamenco. Las primeras recopilaciones de los folkloristas andaluces no llegan a catalogarla dentro de un estilo, apareciendo como "copla" O "cantar", debido a la movilidad entre música y texto antes comentada. Lafuente Alcántara y Rodríguez Marín emplean la evolución del estado amoroso como criterio sobre el que estructurar la clasificación de las coplas populares. Ambos la consideran una copla de celos, quejas y desavenencias. Es curiosa la presencia de la misma entre los "Apuntes para un artículo literario" de la Revista Mensual de Filosofía, Literatura y Ciencias de Sevilla, una de las primeras publicaciones de Antonio Machado Álvarez. El folklorista, con la consideración de copla popular, alaba la belleza de la sugerencia omitida, comparándola con las creaciones del poeta Juan Arolas (Machado 1869, 177). Curiosamente, la copla se silencia en la primera Colección de cantes flamencos, antes citada, que, como comentamos, solo reconoce como popular una copla del ámbito erudito, la de Augusto Ferrán. La segunda gran colección de Machado, Cante flamenco. Colección escogida, sí la incluirá, junto con numerosas coplas de autor (Machado 1887, 115). Creemos que existe una elusión intencionada en la primera colección, en cuyo prólogo hay una férrea defensa de la creación popular frente a la copla culta. De la misma se descuelgan coplas populares de Campoamor o Álvarez Sierra, además de la de Ruiz Aguilera, incluidas en sus primeros artículos sobre el flamenco. Algunos investigadores han querido ver una construcción ficticia de la creación popular, más ajustada al anhelo de combinar la evolución darwinista con las ideas folkloristas (Baltanás 2005, LVII).

Ya en el siglo Xx la localizamos en cancioneros flamencos específicos como malagueña y como fandango. Poseemos un registro sonoro en los tangos de Enrique Morente "A la hora de la muerte" (Morente 1975), que también incluye la estrofa lorquiana de El lenguaje de las flores. En los créditos, el cantaor granadino se otorga la adaptación de las letras. Los controvertidos derechos de autor obligan a esta atribución de registros. La literalidad de la versión de Morente nos hace pensar en una lectura directa del cantar de Ruiz Aguilera, más que en la transmisión oral. En una recopilación póstuma -algo contaminada- de las compilaciones de Fernán Caballero encontramos una versión con modificaciones propias de su uso popular (Anónimo 1914, 199). Un siglo después, Jiménez Quesada cita esta misma variante como malagueña (Jiménez 1974, 96).

Anda ve y dile a tu madre, Si me desprecia por pobre, Que el mundo da muchas vueltas, Que ayer se cayó una torre. (XVII) (Ruiz 1865, 84)
Si tu madre me desprecia, Porque dice que soy pobre, El mundo da muchas vueltas; Ayer se cayó una torre. (Lafuente 1865 II, 241)
Si tu madre no me quiere Porque dice que soy pobre, Los ríos van a la mar Y ayer se cayó una torre. (Jiménez 1974, 96) 
El segundo cantar recogido por Lafuente es el XXXVIII, está basado en la sencilla fórmula indirecta "con un letrero que dice», de enorme éxito en la literatura popular. Francisco Lecha -si no nos encontramos ante un seudónimo-, uno de los escasos nombres de autores de coplas que encontramos en el siglo XVIII, abusa de este recurso entre sus "coplas de la jota" $\mathrm{y}$ "Octavas por el tono de la jota». La difusión de su obra es a través de pliegos de cordel, que se imprimirán numerosas veces en los siglos XVIII y XIX. Citamos algunas de su gran abanico: "Para adorno de tu pecho / llevo un clavel y una rosa / con un letrero que dice: / María es la más hermosa" (Lecha ca. 1760-1770, 1), o «Con letras de plata y oro / he de poner un letrero / que sepa todo el mundo / que soy tu amante verdadero» (Lecha ca. 1816, 3). También es muy frecuente esta fórmula entre los pliegos de jotas y rondeñas de enorme auge entre 1830 y 1850. Si hubiera conocido la obra de Lecha, Ruiz Aguilera podría haber reforzado su defensa del pueblo creativo «donde viven también, y sienten, y piensan, y estudian, y observan, y cantan, hombres de fantasía educada y de mayor dominio del arte, en quienes se encarna, por decirlo así, más vivamente la genialidad propia de su nación» (Ruiz 1866, 252). Destacar la importancia de estos poetas de ingenio en la lírica popular desluce las tristes comparaciones que sufrirá su cantar frente a la versión popularizada. Citamos la opinión de los hermanos Caba Landa en el elogio de la variante frente al cantar original:

... el cantar ganó mucho con ella: primero, porque lo de mañana era solo una cuña para llenar el primer verso; segundo, porque más gente había de leer el letrero puesto en la puerta de la casa, que da a la calle, que en la escalera, que solo da al portal, y tercero, porque aquello de contar palabras es una frialdad rebuscadilla y prosaica, la cual tapó el pueblo dando encima un valiente brochazo de genio. (Caba 1933, 168)

Aunque parece ser evitada en los cancioneros flamencos, finalmente acaba en su corpus, como indican Fernández Bañuls y Pérez Orozco, autores de La poesía flamenca. Lírica en andaluz, la colección más numerosa de coplas flamencas del siglo Xx.

En tu escalera mañana

He de poner un letrero

Con seis palabras que digan

"Por aquí se sube al cielo".

(XXXVIII) (Ruiz 1865, 91)
En la puerta de tu casa

He de poner un letrero

Con letras de oro que digan:

"Por aquí se sube al cielo".

(Fernández y Pérez 1983, 338)

Afirman ambos autores que las más de tres mil coplas que constituyen su colección están documentadas en la voz de algún cantaor consagrado (Fernández y Pérez 1983, 34). No hemos llegado a localizar dicha fuente 
sonora, pero también incluyen el cantar XXXV. Su desarrollo gira en torno al símil de la abeja y la miel, cuya metáfora, además de sabiduría y laboriosidad, posee una fuerte carga religiosa, como afirma Sánchez Ramos en "María: colmena de virtudes" (2016). Nos inclinamos hacia una evocación diferente: la erótica y picaresca. Con esta simbología es muy empleado en la poesía barroca, como identificamos en la copla jocosa del gongorino Miguel Colodrero de Villalobos: «Hermosa Fili, no llores, / ni a la abeja le des quejas, / que es propio de las abejas / el atreverse a las flores..." (Colodrero 1656, 63). La copla se popularizará con leves variantes y será citada en la famosa escena andaluza de Estébanez Calderón, "Un baile en Triana" (Estébanez 1842, 4). Sospechamos de este sentido erótico analizando la tendencia similar que mantiene en el cantar LVI, basado en el refrán «Donde está la miel, están las abejas». Ruiz Aguilera lo plantea como: «Nubes de galanes / siguen a mi bien: / nunca faltan moscas / donde está la miel». La versión popular -no podemos afirmar si es una evolución de su copla o el espejo donde se mira- lo plantea corregido: "Una abeja, en los labios / le picó a mi bien; / siempre van las abejas / donde está la miel».

\section{La abeja busca las flores \\ Para robarles su miel; Mi pensamiento es abeja, Tu boca rojo clavel. \\ (XXXV) (Ruiz 1865, 90)}

Con un sentido más contenido citamos el cantar consecutivo, el XXXVI, uno de los más reconocidos. En las colecciones andaluzas de coplas anónimas se mantiene vivo desde las primeras recopilaciones de la década de 1880, llevadas a cabo por folkloristas como Rodríguez Marín (Rodríguez 1882-1883, IV, 264) o Díaz Martín (Díaz 1884, 29). Posteriormente lo localizamos en el periodo regionalista de transición de siglo, citándose en "La copla andaluza", de los hermanos Álvarez Quintero (Álvarez Quintero 1910, 1). Las décadas de 1930 y 1940 también dan cuenta de él incluyéndolo en el Cancionero: Niño de Marchena (Gil 1941, 16). No deja de aparecer en el denominado "Renacimiento", de la segunda mitad del siglo Xx, como vemos en Flamencos (Bois 1985, 54). El cantar define el anhelo del poeta: "La identificación con el pueblo, y la asimilación de sus sentimientos, pensamientos y expresiones no obligarán al poeta a bajar a la vulgaridad, por el contrario, elevarán la poesía popular al terreno artístico» (De Castro 1988, 305). Luis Montoto, poeta de cantares de la década siguiente, empleará una recreación similar: «Volando de boca en boca / llegó un cantar a mi casa, / y de la miel que traía / dejó una gota en mi alma» (Montoto 1872, 94), que también registrará Enrique Morente (Morente 1982). 
Cantar que del alma sale

Es pájaro que no muere;

Volando de boca en boca

Dios manda que viva siempre.

(XXXVI) (Ruiz 1865, 90)

El cantar CXXVIII juega con la simbología del mar -inagotable en la lírica popular-, con un profundo erotismo implícito, como distinguimos en las cantigas mariñas medievales. Hemos localizado un juego temático cercano en las supervivencias renacentistas que encuentra el profesor Martínez Torner en dos trabajos de campo: en su recopilación personal de la tradición asturiana y en el análisis que desarrolla sobre las anotaciones de campo del etnomusicólogo Kurt Schindler en Soria, en concreto sobre la número 607: «iQuién quiere entrar / conmigo en el río! / iQuién quiere entrar / conmigo a nadar! / - Yo que no sé nadar, morenita, / yo que no sé nadar, entraré. / Yo que no sé nadar, morenita, / yo que no sé nadar, moriré» (Martínez 1966, 357). El cantar nos llega al flamenco desde dos vías diferentes. La primera es la tradición oral, siendo una copla recurrente entre los fandangos populares de las localidades onubenses (Borrero 2005, 71). Muchos de estos estilos locales han adquirido la connotación interpretativa flamenca. Otra vía de llegada al género es debida a la labor de los «letristas». La figura de estos poetas, normalmente cercanos a los intérpretes (productores, representantes, amigos, a menudo de contrastado reconocimiento), refrenda el valor profesional otorgado a este género, que lo aleja de otras manifestaciones folklóricas musicales supeditadas exclusivamente a la primera vía. Su función es la de crear o recrear coplas adecuadas al perfil o rol del artista. En este caso es José Carrasco Domínguez quien recrea la copla de Ruiz Aguilera, para Manuel Mancheño, el Turronero, en los tangos "Ahora me tocó ganar".

Tus ojos verdes recuerdan Niña, son verdes tus ojos Los ojos de mi Rocío El verde color del mar; Como las olas del mar, Son profundos como el mar, ¡Infeliz del que los mire, Pobre del que se mire en ellos,Desgraciao del que la mire Como no sepa nadar! Ay, si no sabe nadar. Como no sepa nadar. (CXXVIII) (Ruiz 1865, 126) (Borrero 2005, 71) ） (Mancheño 1979)

El cantar número I se estructura sobre el verso tópico «la guitarra que toco", que genera multitud de variantes catalogadas principalmente entre los cantes de serenata o de ronda. Algunas muestras contemporáneas a los versos de Ruiz Aguilera podrían ser: "La guitarra que toco / me sirva de sepultura» $\mathrm{O}$ "La guitarra que toco / no tiene prima»; $\mathrm{y}$ en otras agrupaciones las podemos encontrar sobre «el pandero que toco». En la mayoría de las 
ocasiones presentan un tono jocoso, aunque en la antigua lírica popular también se pueden encontrar muestras con un aire sentimental y catártico como el que describe Ruiz Aguilera. Citamos el dístico que recoge Margit Frenk en el Cartapacio de Morán de la Estrella: «Elvira, tus castañetas / para mí fueron saetas» (Frenk 2003 I, 993), o el que recoge en el Vocabulario de refranes, de Gonzalo Correas: «Pandero el mi pandero, / iquién os tañerá si yo muero!» (Frenk 2003 I, 998). El cantar lo encontramos entre los fandangos que recoge Manuel Garrido Palacios en el corpus musical de la localidad onubense de Alosno, una de las cunas del fandango (Garrido 1992, 211). Destacamos una adaptación del cantar por el desconocido letrista Francisco Bruno de Perinat, para el repertorio de fandangos de Paco el Americano (Anónimo 1935, 32). Analizando la discografía del artista creemos que no llegó a registrarse; esto demuestra la dificultad de muchos poetas para ver interpretadas sus creaciones.

La guitarra que yo toco Siente como una persona; Unas veces canta y ríe, Otras veces gime y llora.

(I) (Ruiz 1865, 78)
La guitarra que yo toco

Siente como una persona; Unas veces canta y ríe, Otras veces gime y llora Según como la acaricien. (Perinat 1935, 32)

También destacamos el cantar metafórico CXLVII, de tono intimista. Su seguidora, la poetisa de cantares Isabel de Villamartín, compartirá: «:Espejo vano! / Tiró el tiempo una piedra, / Se hizo pedazos.» (De Villamartín 1865, 98). En el corpus flamenco, el hecho de tirar piedras suele venir asociado al desequilibrio mental, principalmente por causas amorosas que se han elevado a existenciales. Al igual que el anterior, lo encontramos entre los fandangos de Alosno (Garrido 1992, 71). También citamos otro frustrado intento del letrista anterior:

En el árbol de mi vida

Las ilusiones cantaron;

Tiró el dolor una piedra..., ¡Ay de mí! Todas volaron.

(CXLVII) (Ruiz 1865, 133)
En el árbol del dolor

Mis ilusiones posaron

El dolor tiró una piedra

Asustadas se marcharon

Y se cayeron por tierra.

(Perinat 1935, 37)
En el árbol de mi vida Mis ilusiones cantaron, Tiró el dolor una piedra, Las ilusiones volaron.

(Garrido 1992, 71)

El cantar que más registros sonoros presenta es el CL, que ya aparece clasificado entre las malagueñas de las Coplas y cantes flamencos, de Ruperto Chávarri y Batres (Chávarri ca. 1910, 31). Esta colección manuscrita, 
que conserva la Biblioteca Nacional y data en torno a 1910, tiene especial interés por la escasez de colecciones en las dos primeras décadas del siglo XX. La idea que toma Ruiz Aguilera está presente en otras coplas populares de las que destaca: «Sosas eran en lo antiguo / todas las aguas del mar, / pero escupió mi morena / y se volvieron salás", aún viva en el corpus flamenco, y que, atendiendo al vulgarismo, podría proceder del género de costumbres andaluzas que floreció entre 1830 y 1860. La copla de Ruiz Aguilera también se elabora sobre la figura simbólica del agua que mana clara de las fuentes, como metáfora del amor natural, frente al agua turbia -en nuestro caso salada o amarga-, del amor no correspondido, que suele quedar estancada en pozos o lagunas. Esta alegoría atávica ya la distinguimos en "Eres fuente en el jardín, manantial de aguas vivas» de El Cantar de los Cantares de Salomón. Encontramos varios registros sonoros, el primero de ellos, "En el pinar de la fuente», de 1920, en la voz de Fernando Valencia, al estilo de los fandangos o malagueñas con compás que popularizó Juan Breva. Unos años después la encontramos en los fandangos "Yo con un pie me sostengo", del Niño de Marchena, figura emblemática que encumbrará el estilo a partir de esta década. Ambas versiones presentan un verso adicional por el paulatino desarrollo de frases melódicas o «tercios». La configuración actual más frecuente desarrolla seis frases melódicas, que, al adaptarse a cuatro versos, obliga a la repetición de algunos de ellos. El hallazgo de fandangos del siglo XVIII con menos tercios hace sospechar a los investigadores que las estrofas son de creación anterior al canto actual (Castro 2015, 306). La pérdida o ganancia de un verso es muy frecuente en el flamenco por su técnica interpretativa. Muchas soledades de tres versos proceden de antiguas cuartetas que, al perder uno de ellos, aumentan su sentido alegórico y sugerente. La ganancia de un verso, como ocurre en nuestro caso, suele ir en detrimento de esa evocación, elevando el valor narrativo y prosaico. Una década después la recoge Antonio Arévalo entre las alegrías, rosas o juguetes, con un estribillo adicional. Aún sigue viva entre los fandangos tradicionales de Almonaster.

En la fuente de agua dulce En el pinar de la fuente En la fuente del pilar Que hay al pie de la montaña, Que está al pie de la montaña Que está orilla e la montaña, Cayó una lágrima mía... Cayó una lágrima mía Cayó una lágrima mía La fuente se ha vuelto amarga. Y el agua la volví amarga Y el agua se puso amarga. Y era porque te quería.

(CL) (Ruiz 1865, 134) (Valencia, 1920) (Arévalo 1947, 42)

Los cantares XC y LIII también sufren el envite comparativo con la versión popularizada, siempre en detrimento del poeta salmantino. Machado y 
Álvarez llegará a afirmar: «La lección que aquí da el pueblo al poeta erudito es, más que de metrificación, de verdadera estética» (Machado 1883, 70). Manuel Milá y Fontanals sale en su defensa al considerar que «Las modificaciones son felices, pero el mérito de la invención pertenece al poeta culto» (Milá 1893, 240). La belleza e ingenuidad del cantar XC hace que esté muy extendido en la mayoría de las tradiciones musicales hispanas. Entre los cantos andaluces destacamos la referencia del viajero George Whit White en The heart and songs of the Spanish Sierras, que lo cita entre las malagueñas que recoge de los arrieros y campesinos de la serranía rondeña (White 1893, 163). El empresario asidonense Miguel Mihura Álvarez, padre del dramaturgo, recoge el primero como malagueña y el segundo como "chicoleo" (Mihura 1914, 43), entre los curiosos Cantos populares andaluces $y$ algunos originales.

El día en que tú naciste

Cayó un pedazo de cielo;

Cuando mueras y allá subas

Se tapará el agujero.

(XC) (Ruiz 1865, 111)
El día que tú nacistes

Cayó un pedazo de cielo,

Hasta que tú no te mueras

No se tapa el agujero.

(Mihura 1914, 9)
Después de hacerte, Dios quiso

Poner un lunar por firma;

Cogió el sello de su gracia

Y lo estampó en tu mejilla.

(LIII) (Ruiz 1865, 97)

Un tercio de la colección lo constituyen las seguidillas, 106 en total. Esta forma poética había conocido tiempos más felices durante el siglo XVIII e inicios del XIX, con la irrupción del bolero; pero a lo largo del siglo había ido perdiendo favor frente a la cuarteta octosilábica, presente en jotas y fandangos. Aún está presente en algunas tradiciones con seguidillas asentadas en su acervo, como las manchegas, murcianas o sevillanas. El polifacético poeta, actor y recitador cordobés Manrique Gil, muy cercano a los artistas flamencos, colabora en las décadas de posguerra con las editoriales que editan cancioneros de artistas "del momento". Estas editoriales heredan la labor desarrollada por las imprentas de ciegos que habían estado activas hasta 1920. Manrique Gil incluye el cantar LXXVII entre las sevillanas del Cancionero: "Niña de los Peines" (Gil ca. 1945, 26), de la editorial Alas, y del Cancionero: "Niña de la Puebla" (Gil ca. 1955, 9), de la editorial Marazul. La sevillana no la hemos localizado entre sus registros sonoros, de manera que, o bien nos encontramos ante un repertorio inédito, o, en caso contrario, deberíamos hablar de publicaciones de escaso rigor. Es difícil desentramar la alegoría planteada en el cantar, ya que podría tener un sentido amoroso, pero también podría tener una interpretación filosófica atendiendo a las ideas de nuestro poeta, que estuvo muy implicado con el Partido Progresista desde su juventud. Llegó a estar detenido en 1848 por delito de expresión, por artículos en diarios de similar ideario político como La Prensa o La Iberia, y tuvo una participación activa en las movilizaciones 
madrileñas que devinieron en el Bienio Progresista. Junto a Pérez Galdós, eran simpatizantes del krausismo, y participaron en las actividades de la Institución Libre de Enseñanza. Ambos admiraron al mentor de esta rama del pensamiento, el catedrático Julián Sanz del Río, y entablaron amistad con sus discípulos Francisco Giner de los Ríos y Nicolás Salmerón, en las reuniones del Ateneo y las tertulias del Café Universal.

$\begin{array}{ll}\text { Aunque canto, no canto } & \text { Aunque cante, no canto } \\ \text { De buena gana; } & \text { De buena gana; } \\ \text { Yo canto como el ave } & \text { Yo canto como el ave } \\ \text { Presa en su jaula. } & \text { Presa en su jaula. } \\ \text { ¿Cuándo, alma mía, } & \text { ¿Cuándo, alma mía, } \\ \text { De romper tus prisiones } & \text { De romper tus prisiones } \\ \text { Llegará el día? } & \text { Llegará el día? } \\ \text { (LXXVII) (Ruiz 1865, 106) } & \text { (Gil ca. 1945, 26) }\end{array}$

Aún presentes en las pandas de verdiales y otros fandangos colectivos encontramos la copla II. Los investigadores Molina y Gaitán la citan en jA los verdiales voy!, entre los piropos por verdiales (Molina y Gaitán 1999, 61). El símil es el recurso semántico que caracteriza al cantar que, gradualmente, concluye con otra comparación aún más sentenciosa. En un cancionero manuscrito castellano que datamos en torno a 1850, localizamos una copla popular con cierto parentesco al cantar II: «Parece tu rostro bello / cubierto de tanta negrura / a la luna cuando sale / (y) alumbra la noche oscura» (Gil ca. 1850, 6). Álvarez Curiel cita el cantar XXIV en el Cancionero popular andaluz, entre las coplas amorosas (Álvarez 1992, 138). La rima sencilla monosilábica, de menor prestigio en la poesía culta, tiene mejor tolerancia en los aires populares.

Tu pálido rostro, niña, Tiene el altar de mi pecho

Es como noche de luna, Una imagen y una luz;

Y la mata de tu pelo Es la luz el amor mío

De color de noche oscura. Y Y la imagen eres tú.

(II) (Ruiz 1865, 78) (XXIV) (Ruiz 1865, 86) 
5. EL LIBRO DE LA PATRIA. ECOS NACIONALES Y CANTARES. AlGUNOS CANTARES DESCARTADOS

Cuatro años después publica El libro de la patria, que no presenta la repercusión de su anterior colección. Es cierto que algunos de sus cantares serán emblemáticos, como el cantar XXIX: «El cantar, para ser bueno / ha de ser como la cola», o el XXXII: "Un cantar bajó al pueblo, / no era mal mozo", pero no llegan a gozar del favor popular, si analizamos su escasa repercusión en las colecciones de coplas anónimas. Únicamente presentan valores destacables en la colección francesa Chansons populaires espagnols, de Achille Fouquier, conformada a partir de colecciones de cantares cultos; y en el Cancionero aragonés, de Jiménez de Aragón. La tradición musical de la jota acoge el amable sentido jocoso de Ruiz Aguilera, donde dejará una buena escuela de seguidores como Luis Ram de Viu, Luis Royo, Ricardo Catarineu, Alberto Casañal o Sixto Celorrio.

Tabla 2. Cantares de Ruiz Aguilera en algunas Recopilaciones de COPlas populares ANÓNIMAS

\begin{tabular}{|l|c|c|}
\hline \multicolumn{1}{|c|}{ CANCIONEROS GENERALES } & $\begin{array}{c}\text { Armonias y } \\
\text { cantares (1865) }\end{array}$ & $\begin{array}{c}\text { El libro de la } \\
\text { patria (1869) }\end{array}$ \\
\hline $\begin{array}{l}\text { Lafuente Alcántara } \\
\text { (Cancionero popular, 1865) }\end{array}$ & 2 & 0 \\
\hline Anónimo (Flor de epigramas, 1866) & 3 & 0 \\
\hline $\begin{array}{l}\text { Rodríguez Marín } \\
\text { (Cantos populares españoles, 1882-1883) }\end{array}$ & 7 & 10 \\
\hline $\begin{array}{l}\text { Fouquier } \\
\text { (Chansons populaires espagnols, 1882) }\end{array}$ & 32 & 1 \\
\hline Caballero (Gorjeos del alma, 1884) & 1 & 0 \\
\hline $\begin{array}{l}\text { Vergara } \\
\text { (Cantares populares, Castilla la Vieja, 1912) }\end{array}$ & 3 & 0 \\
\hline Rodao (Cantares españoles, 1920) & 5 & 0 \\
\hline Vergara (Mil cantares amorosos, 1921) & 1 & 4 \\
\hline Sevilla (Cancionero popular murciano, 1921) & 6 & 3 \\
\hline $\begin{array}{l}\text { Jiménez de Aragón } \\
\text { (Cancionero aragonés, 1925) }\end{array}$ & 57 & 0 \\
\hline $\begin{array}{l}\text { Vasco } \\
\text { (Treinta mil cantares populares, 1929-1932) }\end{array}$ & 4 & 0 \\
\hline
\end{tabular}

Fuente: Elaboración propia. 
Destacamos entre ellos el cantar XCII, aún vivo en el repertorio andaluz, como recoge Álvarez Curiel (Álvarez 1992, 109). La poetisa Blanca de Gassó erige su obra sobre esta temática ocular: «Hoy me enamoran dos niñas / asomadas a dos rejas: / son las niñas de tus ojos / entre tus pestañas negras» (Gassó 1871, 145). Citamos también dos cantares que recrean la idea que Jorge Manrique expresó en las Coplas a la muerte de su padre. El primero de ellos, el XXII, ya había sido desarrollado de forma muy similar por otros autores de cantares como Rafael de Nieva, en La Violeta (Nieva 1865, 346), o José de Fuentes, en El Imparcial (Fuentes 1867, 3). La coincidencia temática es muy frecuente en la poesía de cantares, más que por imitación, por convergencia de ideas. Otro cantar con aire de Manrique es el VIII, que encontramos en la colección póstuma de Fernán Caballero (Anónimo 1914, 194).

Tras dos cortinas ocultas Las fuentes van a los ríos,

Dos niñas me han vuelto loco: Los ríos van a la mar;

Las cortinas, tus pestañas;

Las niñas, las de tus ojos.

(XCII) (Ruiz 1869, 190)
La vida que va pasando ¡Ay! ¿Quién sabe adónde irá? (XXII) (Ruiz 1869, 165)
Las dichas del hombre duran Lo que las olas del mar;

La que nace, muere al punto,

Y olas vienen y olas van.

(VIII) (Ruiz 1869, 159)

También localizamos en el corpus flamenco el cantar XLIX, que el investigador Mario Bois incluye entre las coplas de "La cour d'amour", de su colección Flamencos (Bois 1985, 91). En él emplea un recurso popular usual, el ave como mensajero de un valor superior. Acude también al recurso de la interrogación retórica, frecuente en las composiciones que pertenecen al ambiente poético becqueriano (De Castro 1988, 309). Cossío ve una evolución en el estilo de Ruiz Aguilera, y considera que en estas últimas publicaciones se aleja de la imitación del cantar popular para buscar nuevas fórmulas y planteamientos que actualicen el género (Cossío 1960, 469).

\footnotetext{
Siempre que cantas acude

Un ruiseñor a tu reja:

-¿Adónde vas?, Le pregunto,

Y me responde: $-\mathrm{A}$ la escuela.

(XLIX) (Ruiz 1869, 175)
}

Por último, citamos una muestra de los cantares que se añaden en futuras ediciones de su obra, como la edición de los Ecos nacionales y cantares de 1873. La copla llega a consolidarse en el corpus anónimo andaluz como recoge Mario Bois en Flamencos (Bois 1985, 91), y en ella emplea el atávico "doble de campanas». Ruiz Aguilera no elude temas cercanos como las coplas carceleras, las fraguas, el patetismo ligado a la muerte o el amor 
filial, muy presentes en el flamenco, pero es cierto que no llegan a cuajar en el género. Es el caso del cantar VIII: «Forman la muerte y la ausencia / en el alma un cementerio»; el CLXVI: "Así que vine yo al mundo / me leyeron la sentencia»; el CXII: "Ya sabes que con el fuego / duros metales se ablandan", o el CLVI: "Para encender mi fragua / no tengo fuelle", son algunos de sus cantares que se mueven en la iconografía flamenca, pero no llegan al repertorio.

\author{
Cuando oigo las campanas \\ Doblar a muerto: \\ ¡Feliz, (digo) la nave \\ Que entra en el puerto! \\ (Ruiz 1873, 309)
}

\title{
6. CONCluSiOnes
}

A lo largo del artículo hemos tratado de mostrar la importancia de Ruiz Aguilera en los cantes andaluces o flamencos siguiendo la técnica imitativa de determinados cantares populares. La calidad de sus creaciones hará que muchos de ellos circulen de forma anónima en determinadas manifestaciones musicales y queden recopilados en los cancioneros con un alto grado de mímesis.

El carácter desenfadado de muchas de sus coplas las aleja de estilos de mayor patetismo como soleares y seguiriyas, pero, en cambio, serán inmediatamente acogidas en malagueñas y fandangos. Otra vía de entrada posterior al flamenco la encontramos en la relectura y adaptación de sus cantares por parte de letristas y cantaores. Aunque muchos investigadores opinen lo contrario, no es un autor tan ajeno a la tradición andaluza.

La reivindicación de la calidad del cantar literario sobre el popular será uno de los grandes litigios en los que se involucra Ruiz Aguilera, junto a la defensa de la condición de autor. Frente al anhelo de Ferrán, cuya humilde aspiración es distinguir «uno solo de ellos de entre un corrillo de alegres muchachas» (Ferrán 1861, 6), Ruiz Aguilera reclama su paternidad, algo paradójico en un autor que basa su técnica en la imitación de cantares anónimos. Curiosamente otros poemas del autor fueron musicalizados en piezas destinadas a las veladas de salón burguesas, como iAy, madre!, para canto y piano, compuesta por J. Espí Ulrich. Estas piezas han quedado fosilizadas en un estrato histórico totalmente ajeno a la aceptación y eternidad de sus cantares, que aún siguen interpretándose.

La voz de Ruiz Aguilera no quedará muda, pese al olvido de la mayor parte de su obra. Su eco se observará en otros poetas de cantares como 
Isabel de Villamartín, Narciso Díaz de Escovar, Ángel Avilés, Luis Royo Villanova, Alfonso Tovar o Carmen de Burgos.

\section{BibliografíA}

Alonso, Celsa. La Canción Lírica Española en el siglo XIX. Madrid: Instituto Complutense de Ciencias Musicales, 1998.

Álvarez Curiel, Francisco. Cancionero popular andaluz. Málaga: Editorial Arguval, 1992.

Álvarez QuinTERO, Serafín y Joaquín. «La copla andaluza. Trabajo leído en la fiesta celebrada en el Ateneo de Madrid en honor de la Copla española, anteayer». El Defensor de Córdoba, Córdoba, 8 de abril de 1910, p. 1.

Anónimo. "Un cantante flamenco». Variedades, El Espectador, Madrid, 6 de junio de 1847 , p. 3.

ANÓNimo. El Contemporáneo, Madrid, 24 de enero de 1863, p. 4.

Anónimo. Obras completas, Fernán Caballero, Apéndice, XVII. Madrid: Tipografía de la Revista de Archivos, 1914.

ANÓNIMO. Flor de epigramas. Madrid: Imprenta de R. Labajos, 1866.

ArÉvalo García, Antonio. La Copla andaluza. Córdoba: Tipografía Artística, 1947.

Baltanás, Enrique. Antonio Machado y Álvarez, Demófilo, Obras completas. Sevilla: Biblioteca de Autores Sevillanos, Diputación de Sevilla y Fundación Machado, 2005.

Blanco, Francisco. La literatura española en el siglo XIX, vol. 2. 2. ${ }^{a}$ ed. Madrid: Sáenz de Jubera Hermanos, editores, 1903.

BoIs, Mario. Flamencos. Une approche du grand chant flamenco et de la poésie populaire chantée en Andalousie. Paris: Éd. Max Fourny, 1985.

Borrero García, Sebastián. 1500 letras de fandango. Sevilla: Signatura Ediciones S. A., 2005.

CABA Landa, Carlos y Pedro. Andalucía, su comunismo libertario y su cante jondo. Madrid: Biblioteca Atlántico, 1933.

CABAllero, Ramón. Gorjeos del alma. Madrid: Biblioteca Universal, 1884.

Castro Buendía, Guillermo. Génesis musical del cante flamenco. Sevilla: Libros con Duende, S. L, 2015.

ChÁvarri y BAtres, Ruperto. Coplas y cantes flamencos. BNE Manuscrito M/12337, ca. 1910.

Colodrero de Villalobos, M. Divinos versos o Cármenes sagrados. Zaragoza: Herederos de Pedro Lanaja y Lamarca, 1656.

Cossío, José María de. Cincuenta años de poesía española (1850-1900), I. Madrid: Espasa-Calpe, 1960.

De Castro García, María Isabel. La poesía de cantares en la segunda mitad del siglo XIX. Madrid: Universidad Complutense de Madrid, 1988.

De Villamartín, Isabel. Horas crepusculares. Madrid: Imprenta de C. González, 1865. 
De Perinat, Francisco Bruno. Figuras del cante jondo. Paco el Americano. Sevilla: Centro Distribuidor de Revistas, Diarios y Publicaciones, 1935.

Díaz Martín, Manuel. Cantares andaluces. Sevilla: Imprenta de El Porvenir, 1884. EDUARDO. "Variedades». La Abeja montañesa, Santander, 24 de septiembre de 1864, p. 3.

Espí UlRich, J. ¡Ay, madre!, para canto y piano. Madrid: Romero y Marzo editores, 1880.

Estébanez Calderón, Serafín. «Un baile en Triana». El Heraldo, Madrid, 1 de diciembre de 1842, p. 4.

Fernández Bañuls, Juan Alberto y José María Pérez Orozco. La poesía flamenca, lírica en andaluz. Sevilla: Servicio de Publicaciones del Ayuntamiento de Sevilla, 1983.

FERRÁn y Forniés, Augusto. La Soledad. Madrid: Imprenta de T. Fornaet, 1861.

FOUQUIER, Achille. Chansons populaires espagnols. Paris: Librairie des Bibliophiles, 1882.

Frenk Alatorre, Margit. Nuevo corpus de la antigua lírica popular hispánica (Siglos XV a XVII). Ciudad de México: Facultad de Filosofía y Letras, unAM, 2003.

Fuentes, José de. Cantares. El Imparcial, Madrid, 26 de abril de 1867.

Garrido Palacios, Manuel. Alosno, palabra cantada. Madrid: Fondo de Cultura Económica, 1992.

GASsó y OrTiz, Blanca de. Cien cantares a los ojos. Madrid: Viuda e hijos de Galiano, 1871.

GELARDO, José. "Acerca del carácter popular de la música flamenca». Contraclave. Revista Digital Educativa, julio, 2016. http://www.contraclave.es/musica/minas/coplaflamenca.pdf [10/06/2020].

Gil, Eduardo. Cantares. (Cancionero manuscrito sin referencias), ca. 1850.

GIL, Manrique. Cancionero Niño de Marchena. Barcelona: Editorial Alas, 1941.

GIL, Manrique. Cancionero popular: La Niña de los Peines. Barcelona: Editorial Alas, ca. 1945.

GIL, Manrique. Cancionero: Niña de la Puebla (El ruiseñor sin luz). Selección de Manrique Gil. Barcelona: Ediciones Marazul, ca. 1955.

Gutiérrez CARBajo, Francisco. La copla flamenca y la lírica de tipo popular. Madrid: Ed. Cinterco, 1990.

IZA DE ZAmacola, Juan Antonio. Colección de las mejores coplas de seguidillas, tiranas y polos que se han compuesto para cantar a la guitarra, vol. I. Madrid: Imprenta de Repullés, 1816.

Jiménez de ARAGón, Juan José. Cancionero aragonés. Zaragoza: Tipografía La Académica, 1925.

Jiménez QuesadA, Manuel. La autenticidad del cante flamenco. Madrid: Ediciones Iberoamericanas, S. A, 1974.

LAFUente AlCÁntara, Emilio. Cancionero popular, colección escogida de coplas y seguidillas, tomo segundo. Madrid: Carlos Bailly-Bailliere, 1865.

LECHA, Francisco. Coplas de la jota, con estrivillos y quartillas, Coplas para Casadas, Viudas, Doncellas. Compuestas nuevamente por el mismo Francisco Lecha, que compuso las de Águila soy del Amor, y la Guirnalda de las Coplas de los 
nombres de Mugeres, ahora nuevamente en este presente año. Barcelona: Imprenta de los herederos de Juan Jolis, ca. 1760-1770.

LECHA, Francisco. Coblas de la Jota, Estrivillos y Cuartillas, Coblas para casadas, viudas, doncellas. Compuestas nuevamente por el mismo Francisco Lecha, que compuso las del Águila soy del Amor, y la Guirnalda de los nombres de Mugeres, abora nuevamente en este presente año. Barcelona: Imprenta de Ignacio Estivill, ca. 1816.

Lledó PatiÑo, Mercedes. Ventura Ruiz Aguilera: escritor y periodista. Tesis doctoral dirigida por Fernández Martínez Vallvey. Universidad Pontificia de Salamanca, 2006.

Longmann, T., J. C. Willhoit y L. Ryken. Gran diccionario enciclopédico de imágenes y símbolos de la Biblia. Barcelona: Editorial CLIE, 2015.

MACHADO y ÁlVAREZ, Antonio. "Apuntes para un artículo literario». Revista Mensual de Filosofía, Literatura y Ciencias de Sevilla, 1869, p. 177.

Machado y Álvarez, Antonio. Colección de cantes flamencos. Sevilla: Imp. y Lit. de El Porvenir, 1881.

Machado y Álvarez, Antonio. Poesía popular: post-scriptum a la obra Cantos Populares Españoles. Sevilla: Francisco Álvarez, 1883.

MaCHADO y Álvarez, Antonio. Cantes flamencos, colección escogida. Madrid: El Motín, 1887.

MARTíNEz TORNER, Eduardo. Lírica hispánica. Relaciones entre lo popular y lo culto. Madrid: Editorial Castalia, 1966.

Minura Álvarez, Manuel. Cantos populares andaluces y algunos originales. Madrid: Jerónimo Mihura, Editor, 1914.

Milá y Fontanals, Manuel. Obras completas del doctor D. Manuel Milá y Fontanals, Coleccionadas por el Dr. D. Marcelino Menéndez y Pelayo. Barcelona: Librería de Álvaro Verdaguer, 1893.

Molina, José y Juan Gaitán. jA los verdiales voy! Málaga: Málaga Digital S. L., 1999.

Montoto Rautentstrauch, Luis. Melancolía. Sevilla: Rafael Baldaraque, 1872.

Montoto Rautenstrauch, Luis. La Musa popular. Sevilla: Imprenta de E. Rasco, 1893.

Nieva, Rafael de. "Cantares». La Violeta, Madrid, 16 de julio de 1865, p. 346.

RoDAO, José. Cantares españoles. Barcelona: Casa Editorial Maucci, 1920.

RodríGuez MARín, Francisco. Cantos populares españoles. Sevilla: Francisco Álvarez y C. ${ }^{\text {a }}, 1882-1883$.

Ruiz Aguilera, Ventura. Ecos nacionales. Alicante: Imprenta y librería de Pedro Ibarra, 1849.

Ruiz Aguilera, Ventura. "Cantares". Almanaque literario de El Museo Universal para 1863, Madrid, 1863, p. 56.

Ruiz Aguilera, Ventura. Armonías y cantares. Madrid: Imprenta y librería de M. Guijarro, Editor, 1865.

Ruiz AguilerA, Ventura. "Sobre la colección de cantares atribuidos al vulgo». Revista Hispano-Americana, Madrid, 27 de noviembre de 1866, pp. 246-254.

Ruiz Aguilera, Ventura. El libro de la patria. Madrid: Imprenta de Gabriel Alhambra, 1869. 
Ruiz Aguilera, Ventura. Ecos nacionales y cantares. $4 .^{a}$ ed. Madrid: Imprenta de la Biblioteca de Instrucciones y Recreo, 1873.

Ruiz FERnÁndez, Manuel. Filosofía del flamenco. El flamenco como objeto de la filosofía; la filosofía como sujeto del flamenco. Tesis doctoral dirigida por Javier Hernández-Pacheco Sanz y Francisco Paula Rodríguez Valls. Universidad de Sevilla, 2019.

SÁnCHEZ RAmos, Valeriano. "María: colmena de virtudes. Las abejas en la simbología mariana barroca». En ARANDA DONCEL, Juan y Ramón DE LA CAMPA CARMONA (coords.). Regina Mater Misericordiae. Estudios históricos, artísticos y antropológicos de advocaciones marianas. Córdoba, 2016, pp. 613-666.

SEvilla, Alberto. Cancionero popular murciano. Murcia: Imp. Sucesores de Nogués, 1921.

SCHUCHARDT, Hugo. Los cantes flamencos (Die Cantes flamencos, 1881). Sevilla: Fundación Machado, 1990.

VAsco, Eusebio. Treinta mil cantares populares, tomos I a IV. Valdepeñas: Imprenta de Mendoza, 1929-1933.

Vergara y Martín, Gabriel María. Cantares populares recogidos en diferentes regiones de Castilla La Vieja y particularmente en Segovia y su tierra. Madrid: Imprenta de Fortanet, 1912.

VERgARA y MARTín, Gabriel María. Mil Cantares populares amorosos. Madrid: Librería de los sucesores de Hernando, 1921.

White, G. Whit. The heart and songs of the Spanish Sierras. Londres: T. F. Unwin, 1894.

\section{GRABACIONES SONORAS}

"FERnANDO VALENCIA» (cante) y S/R (guitarra). "En el pinar de la fuente», (Pizarra). Ref. C-374_. Regal, 1920.

MancheÑo PeÑa, Manuel: «El Turronero» (cante), Francisco López-Cepero García: "Paco Cepero» (guitarra), Enrique Jiménez Ramírez: "Enrique de Melchor» (guitarra), José Carrasco Domínguez (letra), José López-Cepero García(letra). "Ahora me tocó ganar". En Mi sangre. El Turronero. Barcelona: Olivo-Belter, S. A., 1979.

Morente Cotelo, Enrique: «Enrique Morente» (cante), José Manuel Ortega Heredia: "Manzanita" (guitarra), Enrique Morente Cotelo(letra). "A la hora de la muerte (Tangos de Morente)». En Se hace camino al andar. Madrid: Hispavox S. A., 1975.

Morente Cotelo, Enrique: «Enrique Morente» (cante), José Fernández Torres: «Tomatito» (guitarra), Isidro Muñoz Alcín: «Isidro Sanlúcar» (guitarra), Enrique Morente Cotelo (letra). "Cuando un hombre». En Sacromonte. Zafiro-BMG, 1982.

Perea Tejada, José: "Pepe Marchena» (cante), Manuel Serrapí Sánchez: "Niño Ricardo» (guitarra). "Yo con un pie me sostengo" (Pizarra). Ref. RS-867. Regal, 1928. 